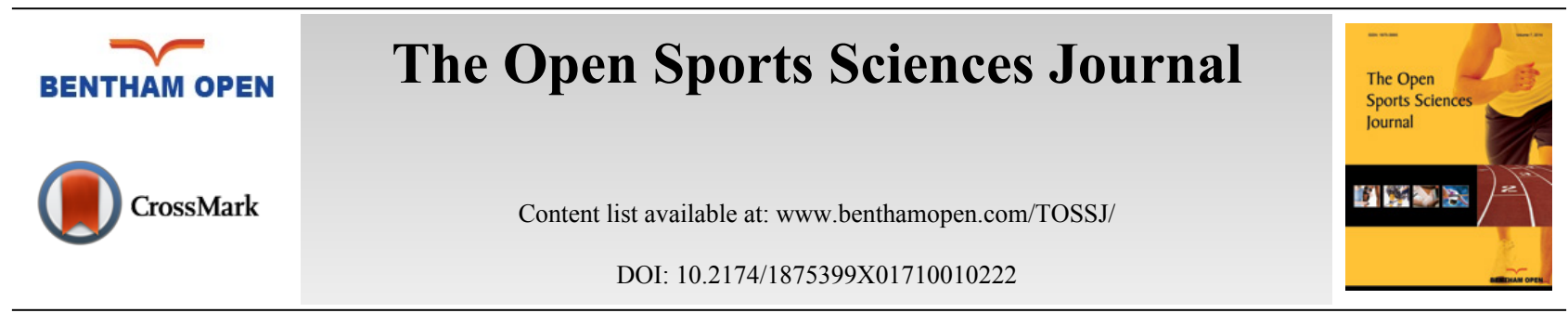

EDITORIAL

\title{
Technologies for Assessment of Training Effects on Health and Performance
}

More and more, the sport science has made use of technologies to evaluate various types of variables in order to improve health and physical performance. The scope of this thematic issue was the new technologies to assess or monitor the effects of a training program or lifestyle habits in physiological, biomechanical or performance variables.

Readers will find studies that used: thermal imaging to identify injury from overtraining, absorptiometry radiological dual energy (DXA) to evaluate body composition, mathematical models, biomechanical gait analysis, biomechanical analysis based on Finite Element Method (FEM), tri-axial accelerometers and force sensors, kinematic analysis, wavelet analysis, biochemical markers, physical activity questionnaires and systematic review.

The sports science progresses to the extent that scientists can access technologies such as those presented in this issue. We hope that readers can understand a little more about technologies applicable to sports science and disseminate its use for the evolution of scientific knowledge in this field.

Eduardo Borba Neves

Brazilian Army Research Institute of Physical Fitness

Rio de Janeiro

Brazil

Abel Rouboa

University of Trás-os-Montes \& Alto Douro

Portugal

Leandro Machado

Faculty of Sport,

Porto University

Portugal

\section{(C) 2017 Neves et al.}

This is an open access article distributed under the terms of the Creative Commons Attribution 4.0 International Public License (CC-BY 4.0), a copy of which is available at: https://creativecommons.org/licenses/by/4.0/legalcode. This license permits unrestricted use, distribution, and reproduction in any medium, provided the original author and source are credited. 